\title{
Microwave Assisted Solvent Free Synthesis of Disulfides with Tributylammonium Halochromates(VI), $\left(\mathrm{C}_{4} \mathrm{H}_{9}\right)_{3} \mathrm{NH}+\left[\mathrm{CrO}_{3} \mathrm{X}\right]-,(\mathrm{X}=\mathrm{F}, \mathrm{Cl})$
}

\author{
Mohammad Kazem Mohammadi and Parya Nasehi
}

\begin{abstract}
Oxidative coupling of thiols to the corresponding symmetrical disulfides were performed in the presence of silica gel supported tributylammonium fluorochromate(VI), (TBAFC), and tributylammonium chlorochromate(VI), (TBACC). TriBAFC and TriBACC are versatile reagents for the effective and selective oxidation of organic substrates, in particular of thiol, in solution and under microwave conditions. Considerable improvements are observed in the presence of the microwave and making the work-up much more convenient.
\end{abstract}

Index Terms-Halochromates, microwave, thiol, disulfide.

\section{INTRODUCTION}

Disulfides are one of the most important organic sulfur compounds possessing an exclusive chemistry both in biochemistry and in synthetic area [1]. Disulfides are also key intermediates in a wide variety of organic synthetic routes. Sweetening of catalyst poisons thiols to low volatile disulfides in oil industries [2] and also industrial applications of disulfides in vulcanization of rubbers and elastomers led us to investigate the introduction and applications of new member of this category of reagents in oxidation of thiols to the corresponding disulfides. Many stoichiometric reagents like manganese dioxide ,dichromates [3], halosilane-chromium trioxide , diethyl azodicarboxylate, nickel peroxide, chromium peroxide, diaryl telluroxide, tetrabutylammonium ceric(IV) nitrate, sodium perborate [4], silver trifluoromethane sulphonate [5] and permangenate [6], [7] have been developed for this transformation. In this research, we wish to report silica gel supported tributhylammonium fluorochromate (TriBAFC) and tributhylammonium chlorochromate (TriBACC) ( TBAXC) able to oxidize thiols to their disulfides efficiently under different reaction conditions

\section{EXPERIMENT}

\section{A. Material and Methods}

$\mathrm{CrO}_{3}$ (Merck, P.A.) was used without further purification. Solvents were purified by standard methods. Infrared spectra were recorded as $\mathrm{KBr}$ disks on a Shimadzu model

Manuscript received June 12, 2015; revised July 20, 2015.

Mohammad Kazem Mohammadi, Parya Nasehi are with Department of Chemistry, Ahvaz Branch, Islamic Azad University, Ahvaz, Iran (e-mail: mohammadi@iauahvaz.ac.ir).
420 spectrophotometer. ${ }^{1} \mathrm{H}$ and ${ }^{13} \mathrm{C}$ NMR (for TEAFC) were carried out on a Bruker AVANCE DRX 500 spectrometer at $500,125,470.66 \mathrm{MHz}$. All the chemical shifts are quoted in ppm using the high-frequency positive convention; ${ }^{1} \mathrm{H}$ and ${ }^{13} \mathrm{C}$ NMR spectra were referenced to external $\mathrm{SiMe}_{4}$. Chromium was estimated iodometrically. In the case of the reduced product of the oxidant, chromium was determined after oxidizing with acidic peroxodisulfate $\left(\mathrm{K}_{2} \mathrm{~S}_{2} \mathrm{O}_{8}\right)$ solution. The relative concentrations of carbon, hydrogen and nitrogen were obtained from the microanalytical laboratories, Department of Chemistry, OIRC, Tehran. Melting points were measured on an Electrothermal 9100 melting point apparatus. Experiments were carried out in closed vessel multimode Microsynth Milstone laboratory microwave oven using a 900 Watts Westpointe microwave operating at $3.67 \mathrm{GHz}$. All experiments had good reproducibility by repeat the experiments in same conditions.

\section{B. Tributylammonium Halochromates (TBAFC)}

$\left(\mathrm{C}_{4} \mathrm{H}_{9}\right)_{3} \mathrm{NH}^{+}\left[\mathrm{CrO}_{3} \mathrm{X}\right]^{-}$A $1 \mathrm{~g} \quad(10 \mathrm{mmol})$ sample of chromium (VI) oxide, $\mathrm{CrO}_{3}$, and $0.9 \mathrm{ml}(20 \mathrm{mmol})$ of $40 \%$ hydrofluoric acid (hydrochloric acid) were added to $20 \mathrm{ml}$ of water in a $100 \mathrm{ml}$ polyethylene beaker with stirring. After 5-7 min the homogeneous solution was cooled to ca. $0-2{ }^{\circ} \mathrm{C}$. To the resultant clear orange solution, tributylamine $(2.35 \mathrm{ml}$, $10 \mathrm{mmol}$ ) was added drop wise with stirring over a period of $0.5 \mathrm{~h}$ and stirring was continued for $0.5 \mathrm{~h}$ at $-4{ }^{\circ} \mathrm{C}$. The precipitated yellowish-orange solid was isolated by filtration on a polyethylene funnel, washed with petroleum ether $(3 \times$ $60 \mathrm{ml}$ ) and dried in vacuum for $2 \mathrm{~h}$ at room temperature Yield: (84\%); mp $134{ }^{\circ} \mathrm{C}, \mathrm{C}_{12} \mathrm{H}_{28} \mathrm{CrFNO}_{3}$ : Calc. C, 47.20; H, 9.24; N, 4.58 Found: C, 46.92; H, 9.64; N, 5.20. I.R. $(\mathrm{KBr}): 914 \mathrm{~cm}^{-1} v_{1}\left(\mathrm{~A}_{1}\right)$ or $v\left(\mathrm{CrO}_{3}\right), 634 \mathrm{~cm}^{-1} v_{2}\left(\mathrm{~A}_{1}\right)$ or $v(\mathrm{Cr}-$ F), $950 \mathrm{~cm}^{-1} v_{4}(\mathrm{E})$ or $v\left(\mathrm{CrO}_{3}\right)$, Electronic absorption at $22321 \mathrm{~cm}^{-1}$, corresponded to ${ }^{1} \mathrm{~A}_{2} \rightarrow{ }^{1} \mathrm{E}\left(\varepsilon=177 \mathrm{M}^{-1} \mathrm{~cm}^{-1}\right)$; $28735 \mathrm{~m}^{-1}$ to ${ }^{1} \mathrm{E} \rightarrow{ }^{1} \mathrm{E}\left(\varepsilon=701 \mathrm{M}^{-1} \mathrm{~cm}^{-1}\right)$ and $35971 \mathrm{~cm}^{-1}$ to ${ }^{1} \mathrm{~A}_{1} \rightarrow{ }^{1} \mathrm{E}\left(\varepsilon=1314 \mathrm{M}^{-1} \mathrm{~cm}^{-1}\right)$. UV/Visible, ${ }^{13} \mathrm{C}$ NMR, ${ }^{1} \mathrm{H}$ NMR and ${ }^{19} \mathrm{~F}$ NMR were all consistent with the TBAFC structure. The above procedure can be scaled up to larger quantities, if desired. The $\mathrm{pH}$ of $0.01 \mathrm{M}$ solution of TBAFC in water was 3.15. Yield: $(71 \%)$; mp $126{ }^{\circ} \mathrm{C}$. Calcd. For $\mathrm{C}_{12} \mathrm{H}_{28} \mathrm{ClCrNO}_{3}$ : C, 44.79; $\mathrm{H}, 8.70 ; \mathrm{N}, 4.35$. Found: $\mathrm{C}$, 44.59; H, 8.81; N, 4.38. IR (KBr): $898 \mathrm{~cm}^{-1} v_{1}\left(\mathrm{~A}_{1}\right)$ or $v\left(\mathrm{CrO}_{3}\right), 436 \mathrm{~cm}^{-1} v_{2}\left(\mathrm{~A}_{1}\right)$ or $v(\mathrm{Cr}-\mathrm{Cl}), 940 \mathrm{~cm}^{-1} v_{4}(\mathrm{E})$ or $v\left(\mathrm{CrO}_{3}\right) \mathrm{cm}^{-1}$. UV/Visible and ${ }^{1} \mathrm{H}-\mathrm{NMR}$ were all consistent with the TBACC structure. Electronic absorption at 21881 $\mathrm{cm}^{-1}$, corresponding to ${ }^{1} \mathrm{~A}_{2} \rightarrow{ }^{1} \mathrm{E}\left(\varepsilon=336 \mathrm{dm}^{3} \mathrm{~mol}^{-1} \mathrm{~cm}^{-1}\right)$; $28089 \mathrm{~cm}^{-1}$ to ${ }^{1} \mathrm{E} \rightarrow{ }^{1} \mathrm{E}\left(\varepsilon=891 \mathrm{dm}^{3} \mathrm{~mol}^{-1} \mathrm{~cm}^{-1}\right)$ and 34965 $\mathrm{cm}^{-1}$ to ${ }^{1} \mathrm{~A}_{2} \rightarrow{ }^{1} \mathrm{~A}_{1}\left(\varepsilon=1178 \mathrm{dm}^{3} \mathrm{~mol}^{-1} \mathrm{~cm}^{-1}\right)$. The $\mathrm{pH}$ of 0.01 $\mathrm{M}$ solution of TBACC in water was 2.9 (see Fig. 1). 


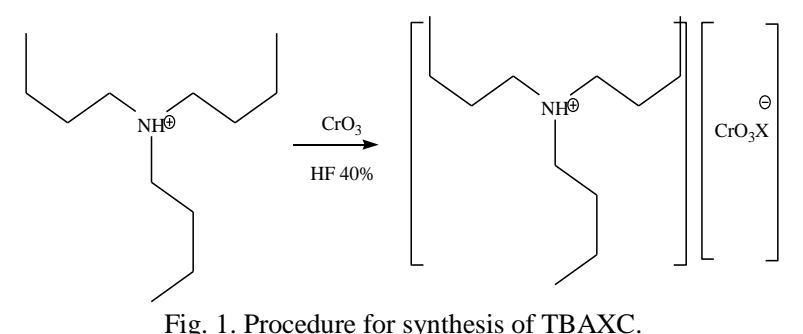

\section{General Procedure for Preparation of Alumina Supported Reagents}

To the cold solution of TriBAFC or TriBACC, prepared by the the above procedure neutral $\mathrm{Al}_{2} \mathrm{O}_{3}$ (Aldrich, - 150 mesh) is added. 30 min evaporation of the solvent under vacuum affords orange - red slurry, which is completely dried on the surface of highly dried day plate in the air.

\section{General Procedure for Oxidation of Thiols with TriBAFC and TriBACC under Microwave Condition}

To a stirred suspension of tributylammonium halochromate $(1 \mathrm{mmol})$ in acetonitrile (generally $5 \mathrm{ml}$ ), a solution of the substrate in the minimum amount of acetonitrile was added drop wise. The molar ratio of substrate to the oxidant being 1:1. The mixture was irradiated for the time indicated in the table by microwave radiation. The completion of the reaction was followed by UV and TLC using ether/petroleum ether (60/40) as eluant]. The mixture was diluted with ether $(1: 1 \mathrm{vol} / \mathrm{vol})$ and filtered through a short column of silica gel to give a clear solution. The solution was evaporated and the residual product purified by distillation, recrystallization or column chromatography. The progress of the reactions were also monitored and checked by UV spectrophotometry. The amount of the oxidant during the reaction was measured spectrophotometrically at $350 \mathrm{~nm}$ (see Table I).

Charactrictic data for synthesized compounds were:

1,2 - diisopropyldisulfane (2a). IR (KBr) $\mathrm{cm}^{-1} 3000$ 2900 C-H(aliph . strech), 1400-1350 C-H (aliph .bend), 1200- $1100 \mathrm{C}-\mathrm{S}$ (strech ). ${ }^{1} \mathrm{H}$ NMR $\left(300 \mathrm{MHz}, \mathrm{CDCl}_{3}\right) \delta$ $2.7(\mathrm{~m}, 2 \mathrm{H}), 1.5(\mathrm{~d}, 12 \mathrm{H}) \cdot{ }^{13} \mathrm{C} \mathrm{NMR}\left(300 \mathrm{MHz}, \mathrm{CDCl}_{3}\right) \delta$ 38.5 (d) , 24(q) . HRMS Calcd for $\mathrm{C}_{6} \mathrm{H}_{14} \mathrm{~S}_{2}: \mathrm{M}^{+}, 150.4125$ Found : $m / z$ 150.4117(average). oil

1,2- dipentyldisulfane (2b). IR (KBr) cm $\mathrm{cm}^{-1} \quad 3000-2900$ $\mathrm{C}-\mathrm{H}$ (aliph . strech) 1200- $1100 \mathrm{C}-\mathrm{S}$ (strech ). ${ }^{1} \mathrm{H}$ NMR (500 $\left.\mathrm{MHz}, \mathrm{CDCl}_{3}\right) \delta 2.5(\mathrm{t}, 4 \mathrm{H}), 1.6(\mathrm{~m}, 4 \mathrm{H}), 1.25(\mathrm{~m}, 4 \mathrm{H}) 1.3$ $(\mathrm{m}, 4 \mathrm{H}), .85(\mathrm{t}, 6 \mathrm{H}) .{ }^{13} \mathrm{C} \mathrm{NMR}\left(125 \mathrm{MHz}, \mathrm{CDCl}_{3}\right) \delta 36$, 33, 31, 23.5, 14.5. HRMS Calcd for $\mathrm{C}_{10} \mathrm{H}_{22} \mathrm{~S}_{2}: \mathrm{M}^{+}$, 206.8542 . Found: $m / z$ 206.1654(average). oil

1,2 - dioctyldisulfane (2c) .IR (KBr) $\mathrm{cm}^{-1} 3000-2900 \mathrm{C}$ $\mathrm{H}$ (aliph . strech) 1200- $1100 \mathrm{C}-\mathrm{S}$ (strech ). ${ }^{1} \mathrm{H}$ NMR (500 $\left.\mathrm{MHz}, \mathrm{CDCl}_{3}\right) \delta 2.6(\mathrm{t}, 4 \mathrm{H}), 1.5(\mathrm{~m}, 4 \mathrm{H}), 1.2(\mathrm{~m}, 18 \mathrm{H}) .9$ $(\mathrm{t}, 6 \mathrm{H}) .{ }^{13} \mathrm{C} \mathrm{NMR}\left(125 \mathrm{MHz}, \mathrm{CDCl}_{3}\right) \delta 33.66,32.5,31.43$, $31.35,31.22,27.03,23.5$, 15.02. HRMS Calcd for $\mathrm{C}_{16} \mathrm{H}_{34} \mathrm{~S}_{2}: \mathrm{M}^{+}, 290.1213$. Found : $\mathrm{m} / \mathrm{z}$ 290.3564(average). oil

1,2 dicyclohexyl disulfane (2d). IR $(\mathrm{KBr}) \mathrm{cm}^{-1} 3000-$ $2900 \mathrm{C}-\mathrm{H}\left(\right.$ aliph . strech), 1200- $1100 \mathrm{C}-\mathrm{S}$ (strech ). ${ }^{1} \mathrm{H}$ NMR $\left(500 \mathrm{MHz}, \mathrm{CDCl}_{3}\right) \delta 2.5(\mathrm{~m}, 2 \mathrm{H}), 1.65(\mathrm{dt}, 8 \mathrm{H})$, $1.4(\mathrm{~m}, 12 \mathrm{H}) .{ }^{13} \mathrm{C}$ NMR $\left(125 \mathrm{MHz}, \mathrm{CDCl}_{3}\right) \delta 52.56,34.52$, 26.59, 25.38. HRMS Calcd for $\mathrm{C}_{12} \mathrm{H}_{22} \mathrm{~S}_{2}: \mathrm{M}^{+}, 230.2135$. Found: $m / z 230.2120$ (average). oil

disulfanyl-acetic acid (2e) .IR (KBr) cm $\mathrm{cm}^{-1}$ 3500-3200 $\mathrm{COOH}$ ( strech) , 3000-2900 C-H(aliph . strech) ,1200- 1100 $\mathrm{C}-\mathrm{S}$ (strech ). ${ }^{1} \mathrm{H}$ NMR $\left(500 \mathrm{MHz}, \mathrm{CDCl}_{3}\right) \delta 2.27$ (s , $4 \mathrm{H}), 11.5(\mathrm{~s}, 2 \mathrm{H}) \cdot{ }^{13} \mathrm{C} \mathrm{NMR}\left(125 \mathrm{MHz}, \mathrm{CDCl}_{3}\right) \delta 35(\mathrm{t})$, 179 (s) . HRMS Calcd for $\mathrm{C}_{4} \mathrm{H}_{6} \mathrm{O}_{4} \mathrm{~S}_{2}: \mathrm{M}^{+}, 182.1478$, Found: $m / z$ 182.342(1average). oil

1,2 diphenyldisulfane (2f). IR $(\mathrm{KBr}) \mathrm{cm}^{-1} \quad 3200-3100$ $\mathrm{C}-\mathrm{H}\left(\mathrm{Ar}\right.$. strech) , 1200- $1150 \mathrm{C}-\mathrm{S}$ (strech ). ${ }^{1} \mathrm{H}$ NMR (500 $\left.\mathrm{MHz}, \mathrm{CDCl}_{3}\right) \delta 7.65(\mathrm{~d}, 4 \mathrm{H}), 7.25(\mathrm{~m}, 6 \mathrm{H}) .{ }^{13} \mathrm{C} \mathrm{NMR}$ $\left(125 \mathrm{MHz}, \mathrm{CDCl}_{3}\right) \delta 133,131.4,130.2,129.53 . \mathrm{C}_{12} \mathrm{H}_{10} \mathrm{~S}_{2}$ : Calc. C, 66.1; H, 4.71; S, 29.37. Found: C, 66.22; H, 4.65; S, 29.2 . m.p. $57-58{ }^{0} \mathrm{C}$.

1,2-di-p- tolyldisulfane or bis(4methylphenyl)disulfide( $2 \mathrm{~g}$ ). IR (KBr) $\mathrm{cm}^{-1} 3200-2100 \mathrm{C}-$ $\mathrm{H}(\mathrm{Ar}$. strech) , 3000-2900 C-H(aliph . strech) 1480-1400 C-H (Ar.bend) ,1200- $1100 \mathrm{C}-\mathrm{S}$ (strech ) . ${ }^{1} \mathrm{H}$ NMR (500 $\left.\mathrm{MHz}, \mathrm{CDCl}_{3}\right) \delta 7.5(\mathrm{~d}, 4 \mathrm{H}), 7.2(\mathrm{~d}, 4 \mathrm{H}), 2.5(\mathrm{~s}, 6 \mathrm{H}) \cdot{ }^{13} \mathrm{C}$ NMR $\left(125 \mathrm{MHz}, \mathrm{CDCl}_{3}\right) \delta 126(\mathrm{~S}), 130$ (d), 127 (d), 124 (s) , 21 (q) . $\mathrm{C}_{14} \mathrm{H}_{14} \mathrm{~S}_{2}$ : Calc. C,68.29; H, 5.70; S, 26.1. Found: C, 68.46; H, 5.60; S, 26.23 . m.p . $42-44^{0} \mathrm{C}$.

1 - ( $n$ - naphthalene $-3-y l)$-2- (naphthalene - 6- yl) disulfane (2h) . IR (KBr) $\mathrm{cm}^{-1}$ 3200-3100 C-H(Ar. strech), 1200- $1150 \mathrm{C}-\mathrm{S}$ (strech ). ${ }^{1} \mathrm{H}$ NMR (300 MHz, $\left.\mathrm{CDCl}_{3}\right) \delta 8.1(\mathrm{~s}, 2 \mathrm{H}), 7.7(\mathrm{~d}, 2 \mathrm{H}), 7.5(\mathrm{~d}, 6 \mathrm{H}) 7.32(\mathrm{~d}, 4 \mathrm{H})$. ${ }^{13} \mathrm{C}$ NMR $\left(300 \mathrm{MHz}, \mathrm{CDCl}_{3}\right) \delta 137.76,137.11,135.26$, 134.52, 131.57, 128.92, 127.08, 126.16, 125.02, 124.87. $\mathrm{C}_{20} \mathrm{H}_{14} \mathrm{~S}_{2}$ : Calc. C,75.47; H, 4.40; S, 20.12. Found: C, 75.36; H, 4.32; S, 20.89 . m.p . 140-142 ${ }^{0} \mathrm{C}$.

\begin{tabular}{|c|c|c|c|c|c|}
\hline \multirow[b]{2}{*}{ Substrate } & \multicolumn{3}{|c|}{ Solution } & \multicolumn{2}{|c|}{ Solution under Microwave } \\
\hline & $\begin{array}{l}\text { Time } \\
(\mathrm{min})\end{array}$ & Product & $\begin{array}{l}\text { Yield } \\
(\%)\end{array}$ & $\begin{array}{l}\text { Time } \\
(\mathrm{min})\end{array}$ & $\begin{array}{c}\text { Yield } \\
(\%)\end{array}$ \\
\hline $\begin{array}{c}\mathrm{CH}_{3}-\mathrm{CH}-\mathrm{SH} \\
\mathrm{CH}_{3}\end{array}$ & 55 & $\stackrel{\mathrm{CH}_{3} \text {-CH-S-S-CH-CH}}{\mid}{\stackrel{\mathrm{CH}}{3} \quad \mathrm{CH}_{3}}^{\mid}$ & 75 & 6 & 85 \\
\hline $1 \mathrm{a}$ & & $2 \mathrm{a}$ & & & \\
\hline $\begin{array}{c}\mathrm{n}-\mathrm{C}_{5} \mathrm{H}_{11}-\mathrm{SH} \\
1 \mathrm{~b}\end{array}$ & 54 & $\begin{array}{c}\mathrm{C}_{5} \mathrm{H}_{11}-\mathrm{S}-\mathrm{S}-\mathrm{C}_{5} \mathrm{H}_{11} \\
2 \mathrm{~b}\end{array}$ & 78 & 7 & 85 \\
\hline $\begin{array}{c}\mathrm{n}-\mathrm{C}_{8} \mathrm{H}_{17}-\mathrm{SH} \\
1 \mathrm{c}\end{array}$ & 60 & $\begin{array}{c}\mathrm{C}_{8} \mathrm{H}_{17}-\mathrm{S}-\mathrm{S}-\mathrm{C}_{8} \mathrm{H}_{17} \\
2 \mathrm{c}\end{array}$ & 72 & 10 & 83 \\
\hline
\end{tabular}


<smiles>SC1CCCCC1</smiles>

HOOC- $\mathrm{CH}_{2}-\mathrm{SH}$

$1 \mathrm{e}$

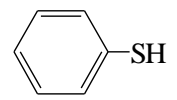

1f

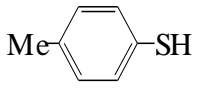

$1 \mathrm{~g}$

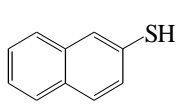

$1 \mathrm{~h}$
50

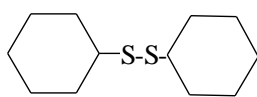

$2 \mathrm{~d}$

56

HOOC-CH $-\mathrm{CH}_{2}-\mathrm{S}-\mathrm{H}_{2} \mathrm{COOH}$

$2 \mathrm{e}$

73

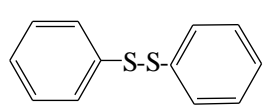

2f

67
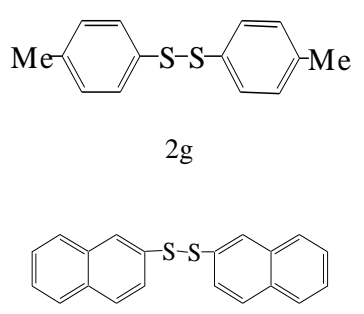

68

77
89

5

8

92

6

84

$2 \mathrm{~h}$
14

81

\section{RESULTS AND DISCUSSIONS}

TBAXC was an easily prepared reagent, which was used for oxidation of alcohols recently. The oxidative coupling of thiols with this reagent was investigated in acetonitrile at room temperature and in dichloromethane solution under microwave radiation. As shown in Table I, a series of aliphatic and aromatic thiols were reacted with 1 molar equivalent of the reagent to afford the corresponding disulfides in excellent yields. This oxidation is also performed under microwave conditions with 1 molar equivalent of the reagent. The results show that under microwave condition, the reaction times were shorter.

TBAXC was used for the oxidation of some organic thiols under microwave irradiation in $\mathrm{CH}_{3} \mathrm{CN}$ as solvent. This method offers some advantages in term of simplicity of performance, simple operation condition, no side product formation, very low reaction time and a wide range of substrates could be converted to their corresponding disulfides. In addition, the reduced reagent $\left(\mathrm{C}_{4} \mathrm{H}_{9}\right)_{3} \mathrm{~N}^{+} \mathrm{CrO}_{2}$ $\mathrm{X}^{-}$could also be recycled after oxidation. TBAXC was very well reagent for the oxidant based on quaternary ammonium halochromates. Thus, the said oxidative method under mild conditions was set out to minimize the dispersion of offensive materials in the environment and was maximized the use of renewable resources. From this standpoint, this method could be considered as a relatively green technology having more advantages and wider applicability, compared to the conventional oxidative reagents (see Table I).

It seemed from the Table I that the time and yield of the disulfide formation reaction with TBAFC and TBACC were in general better than other reported reagents. this different was highlighted when the reagent compared with our reported reagent especially in time of the reaction . by compare of the reagents in table, It was noticed that the time of the disulfide formation reaction with TBAFC and TBACC was reduced effectively rather than yield of the reaction .
Over-oxidation was not been observed, even though the reactions were carried out various conditions (Scheme 1).

In our research on oxidation processes, TBAXC as an oxidant was a very well suited reagent for microwave synthesis, because as an ionic and magnetically retrievable material, it carries a benefit of efficient conversion of electromagnetic energy into heat according to the dielectric heating mechanism (see Table I and Fig. 1).

\section{CONCLUSION}

The present procedure using Triethylammonium halochromates (TBAXC) in solvent and microwave conditions has been found to oxidize selectively primary aliphatic, aromatic and allylic thiols to corresponding disulphides without isomerization and polymerization of double bonds, over oxidation and other side-reactions keeping intact the acid sensitive functionalities, (Scheme 2) .The important advantages of this procedure include (a) operational simplicity (ease of set up and work-up), (b) good yield of the oxidized products, with high purity (by immobilization of the chromium by-products on the surface of silica), (c) mild reaction conditions, (d) good selectivity and (e) general applicability accommodating a variety of substitution patterns.

\section{ACKNOWLEDGMENT}

The author thanks Dr. Sh. Ghammamy for valuable discussion .

\section{REFERENCES}

[1] L. F. Fieser and M. Fieser, Reagents for Organic Synthesis, New York Wiley, vol. 1-11, 1967-1984.

[2] V. Srivastav, R. Gupta, and R. R. Guptam, "Single step synthesis of 4-H- 1,4- benzothiazines," Ind. J. Chem, vol. 39B, p. 223, 2000.

[3] D. L. Holbrook, Handbook of Petroleum Refining Processes, R. A. Meyers Ed., McGraw Hill,1996, ch. 11, p. 3.

[4] C. Lopez, A. Conzales, and C. Cossio, "3-carboxypyridinium dichromate (NDC) and (4-carboxypyridinium dichromate (INDC). 
two new mild, stable, efficient, and inexpensive chromium (VI) oxidation reagents," Synth. Commun, vol. 15, p. 1197, 1985.

[5] A. Mckillop, D. Koyuncu, A. Krief, W. Dumont, P. Renier, and M .Trabelsc, "Effcient, high yield oxidation of thiols and selenols to disulphides and diselenides," Tetrahedron Lett., vol. 31, p. 5007, 1990.

[6] H .Tamamura, A. Otaka, J. Nakamura, K. Okubo, T. Koide, K. Ikeda, and N. Fujii, "The international organ for the rapid publication of preliminary communications in organic chemistry (Amsterdam: Elsevier)," Tetrahedron Lett, vol. 34, p. 4931, 1993.

[7] N. A. Noureldin, M. Coldwell, J. Hendry, and D. G. Lee, "Heterogeneous permanganate oxidation of thiols," Synthesis, vol. 11, p. $1587,1998$.

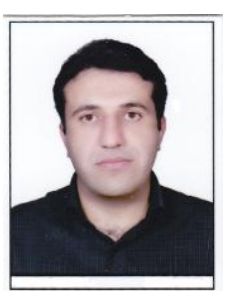

Mohammad Kazem Mohammadi was born in Shiraz (Iran) in 1979. He completed his Ph.D in synthetic orhisganic chemistry (medicinal chemistry) in 2010 and is presently looking for a post-doc position in organic or medicinal chemistry. The title of his $\mathrm{Ph} . \mathrm{D}$ thesis is synthesis of new heterocyclic compounds from carbonyl compounds and others. During his Ph.D period, he had synthesized a series of novel derivatives of pyrimidine and dihydropyrimidon molecules using various types of reactions. During the completion of his MSc degree, he had worked on the synthesis of phase transfer quaternary ammonium catalysts with mild oxidizing ability. During his Ph.D period, he also succeeded in establishing the new methodologies for various reactions and synthesis of new heterocyclic compounds with potential biological activity. He had joined in Shiraz medicinal and natural products chemistry research center, as a research associate. There $\mathrm{He}$ was associated in the $\mathrm{R} \& \mathrm{D}$ of process laboratory. He was involved in the establishing the synthetic route of various target molecules as well as in the scaling up of reactions from milligram to kilogram scale. He was also successfully supervised few batches in plant for synthesis of molecules in multi kilogram scale. He has got well training about IR, NMR, MS and other experimental instruments. Here He has got experiences in validation; scale up, impurity profiles which helpful for me to develop his skill in synthetic organic chemistry.

Presently he is working as a research scientist as an assistant professor of organic chemistry in Islamic Azad University, Ahvaz Branch and Shiraz Medicinal and Natural Products Research Center, Iran. 